\title{
Collagen Synthesis in Normal and Osteoarthritic Human Cartilage
}

\author{
Louis Lippiello, Dale Hall, and Henry J. Mankin \\ From the Orthopaedic Research Laboratories, Massachusetts General Hospital, Boston, Massachusetts \\ 02114
}

A B S T R A C T Collagen metabolism in osteoarthritic human articular cartilage was compared to that in normal cartilage and was also correlated with the degree of severity of the osteoarthritic lesion as determined by a histological-histochemical grading system.

No correlation was apparent between the concentrations of DNA, hydroxyproline, and hydroxylysine and the degree of severity of the osteoarthritic lesion (except in far-advanced lesions). Similarly, there was no correlation in levels of these components in tissues from the normal vs. osteoarthritic group. The similarity of the values of the ratio hydroxylysine/hydroxyproline in osteoarthritic tissue compared with normal, and the lack of variation in these with increasing severity of the disease process argues against the possibility that osteoarthritis is associated with a major shift in the synthesis of type II collagen to type I.

$\left[{ }^{3} \mathrm{H}\right]$ Proline incorporation into osteoarthritic cartilage was increased fourfold as compared to normal cartilage and varied with advancing histological-histochemical grade. Measurement of the specific activity of insolubilized hydroxyproline-containing material of the cartilage matrix, as an index of the turnover of collagen, showed a sixfold increase in osteoarthritic cartilage which also varied with grade. These data suggest that collagen synthesis in these tissues is substantially greater than in nonosteoarthritic tissues and varies directly with the severity of the disease process up to a point and then varies inversely as the lesion becomes more severe.

\section{INTRODUCTION}

Articular cartilage is a specialized form of connective tissue which is characterized by a preponderance of

This work was presented in part at the 22nd Annual Meeting of the Orthopaedic Research Society in New Orleans, La., 28-30 January 1976.

Received for publication 19 May 1976 and in revised form 16 December 1976. a hyperhydrated organic matrix $(1,2)$. The two principal components of the extracellular material are: a relatively insoluble collagen $(2,3)$, accounting for approximately $55 \%$ of the dry wt; and proteoglycan, a complex macromolecular material consisting of a linear protein core to which are affixed glycosaminoglycan chains of varying length and composition (4). These matrix components are synthesized locally by the chondrocytes and despite the "inert" appearance of the tissue, there is now ample evidence to suggest that at least a small portion of the proteoglycan has a rapid turnover $(5,6)$. This view is further confirmed by recent reports that several enzyme systems are present within the tissue, which have as their substrate the proteoglycan and its component biochemical moieties, and are presumed responsible for the catabolic phase of the metabolic cycle $(7-11)$.

The collagen of articular cartilage is considered to be much more stable than the proteoglycan, and until recently there was little evidence for metabolic activity. The appearance of this material on light and electron microscopy (11), metabolic assays (5), and the failure to find a collagenase in normal cartilage (12) supported the contention that the collagen of cartilage turns over very slowly, if at all. In 1972, Repo and Mitchell (13) reported an experiment which demonstrated a slow but measurable turnover of the collagen of articular cartilage in adụlt rabbits and a slight increase in the turnover rate in animals in whom the cartilage surfaces had undergone lacerative injury. These data suggested that the collagen of articular cartilage was not entirely stable and that the chondrocyte could respond to injury by an increased rate of synthesis of collagen.

Studies of the metabolism of articular cartilage from osteoarthritic human joints have demonstrated a marked increase in the rates of incorporation of labeled precursors of the proteoglycan macromolecule (5, 14-16). This has led to the now generally accepted view that, in osteoarthritis, there is an accelerated rate of synthesis of this material (15) which appears 
TABLE I

Histological-Histochemical Grading*

Grade

$\begin{array}{ll}\text { Structure } & 0 \\ \text { Normal } & 1 \\ \text { Surface irregularities } & 2 \\ \text { Pannus and surface irregularities } & 3 \\ \text { Clefts to transitional zone } & 4 \\ \text { Clefts to radial zone } & 5 \\ \text { Clefts to calcified zone } & 6 \\ \text { Complete disorganization } & 0 \\ \text { Cells } & 1 \\ \text { Normal } & 2 \\ \text { Diffuse hypercellularity } & 3 \\ \text { Cloning } & \\ \text { Hypocellularity } & 0 \\ \text { Safranin O staining } & 1 \\ \text { Normal } & 2 \\ \text { Slight reduction } & 3 \\ \text { Moderate reduction } & \\ \text { Severe reduction } & \text { No dye noted } \\ \text { Tidemark integrity } & \\ \text { Intact } & \\ \text { Crossed by blood vessels } & \end{array}$

* Serial histological sections, cut at $5 \mu \mathrm{m}$ and stained with hematoxylin and eosin and safranin $\mathrm{O}$, fast green, and iron hematoxylin, were analyzed for abnormalities in structure, cell population, safranin $\mathrm{O}$ stain distribution, and tidemark integrity and scores were assigned as the histologicalhistochemical grade. Reproduced from Mankin, H. J., H. Dorfman, L. Lippiello, and A. Zarins. 1971. J. Bone Jt. Surg. Am. Vol. 53: 523, with permission of the editor.

to parallel the severity of the disease (16) and is proportional to a depletion of this component in the matrix (16). The enzyme systems necessary to mediate the observed decrease in proteoglycan concentration have been noted to have increased activity in osteoarthritis $(17,18)$ and a prior study from this laboratory (19) has demonstrated a progressive increase in acid phosphatase (as a marker enzyme for autolytic lysosomal systems) with increasingly severe degrees of the disease.

In 1974, Ehrlich et al. (12) reported the finding of a collagenase within the substance of human articular cartilage from osteoarthritic femoral heads which was not present in normal tissues. This finding was helpful in explaining the mechanisms by which end-stage osteoarthritis (characterized by total loss of cartilage) occurred. Since the collagenase was also noted to be present in early lesions as well as late, the data suggested that collagen may be more metabolically active in osteoarthritic cartilage.
The purpose of this paper is to report on experiments in which rates of collagen synthesis in cartilage samples from normal and osteoarthritic human hip joints were assayed by radiotracer techniques. On the basis of the data obtained, an approximately sixfold increase in the incorporation rate of proline into hydroxyproline was demonstrated in articular cartilage in osteoarthritis as compared with normal. This accelerated synthetic activity appears to parallel the severity of the disease, as measured by a histologicalhistochemical grading system.

\section{METHODS}

33 human femoral heads were obtained in the fresh state from patients at the time of surgery. Three of these were normal (two from patients undergoing an Austin-Moore prosthetic replacement for fracture and one from a patient in whom a hip disarticulation was performed for fibrosarcoma). The remaining 30 were considered to be osteoarthritic (obtained at the time of total hip replacement). The average ages of the normal and osteoarthritic groups were 57 and 56 $y r$, respectively. On each femoral head, one, two, or three areas were selected which appeared to be representative of the disease process. Special care was taken to exclude osteophytic, newly formed repair tissue or fibrocartilage (20). In all, 45 areas ( 7 normal and 38 osteoarthritic) were studied.

At the time of resection of the femoral head, full depth cartilage segments were resected from areas approximating $1 \mathrm{~cm}^{2}$ in size (taking care to exclude the underlying bone) and divided into four portions. A segment, consisting of a $1.0 \times 0.3-\mathrm{cm}$ slice, was taken from the center of the square, fixed in $10 \%$ phosphate-buffered formalin, dehydrated, imbedded in paraffin, and then cut at $5 \mu \mathrm{m}$ for histologic sections which were stained with hematoxylin and eosin and safranin $O$, iron hematoxylin, and fast green. These slices were subsequently used to define the severity of the osteoarthritic process by a histological-histochemical grading system previously described from this laboratory (16). A second segment, similar in size, was analyzed for DNA by the indole method of Bonting and Jones (21). The remaining two portions of tissue were incubated at $37^{\circ} \mathrm{C}$ with $100 \mu \mathrm{Ci}$ of $\left[{ }^{3} \mathrm{H}\right]-$ proline (New England Nuclear, Boston, Mass.; sp act, 24.5 $\mathrm{mCi} / \mathrm{mM}$ ) in $3 \mathrm{ml}$ Ham's $\mathrm{F}-12$ media for $6 \mathrm{~h}$ in air and in a Rollerdrum incubator (New Brunswick Scientific Co., Inc., New Brunswick, N. J.). The incubation was terminated by washing the cartilage segments with cold saline and immersion for $18 \mathrm{~h}$ at $4^{\circ} \mathrm{C}$ in a nonisotopic proline solution (100 $\mathrm{mM}$ in normal saline). After dehydration of the segments with absolute ethanol, they were divided into two groups and separately weighed to the nearest microgram.

One group was homogenized using a motor-driven all glass Duall tissue grinder (Kontes Co., Vineland, N. J.) and the homogenate precipitated with cold $10 \%$ TCA (final concentration). Each precipitate was collected after the addition of $20 \mathrm{mg}$ of Celite Filter Aid (Johns-Manville, Denver, Colo., L-665-A) on Whatman filter paper held in Millipore filter holders (Millipore Corp., Bedford, Mass.) and sequentially washed with cold $10 \%$ TCA, absolute ethanol, ethanol: ethyl ether (1:1), and ethyl ether. The precipitation pad was scraped into vials, solubilized with $0.5 \mathrm{ml}$ of hydroxide of hyamine, and then counted in a liquid scintillation counter using Omnifluor (New England Nuclear) in a toluene base.

For the determination of radioactivity associated with hydroxyproline, the second group of labeled cartilage seg- 
ments was hydrolyzed in Pyrex tubes (Corning Glass Works, Corning, N. Y.) in $6 \mathrm{~N} \mathrm{HCl}$ at $110^{\circ} \mathrm{C}$ for $18 \mathrm{~h}$. The hydrolysates were dried in vacuo and the amino acids were separated on cellulose-coated glass thin-layer plates (Merck Chemical Div., Merck \& Co., Inc., Rahway, N. J.) in a phenol: methanol:water system (6:11:3 vol/vol) (22). Radioactivity associated with hydroxyproline was determined by scraping into vials those zones corresponding to standard hydroxyproline (localized by spraying the standards with ninhydrin). The cellulose-containing amino acids were suspended in $0.5 \mathrm{ml}$ water, heated for $10 \mathrm{~min}$ at $60^{\circ} \mathrm{C}$, and counted in a liquid scintillation counter using Aquasol (New England Nuclear). Radiolabeled hydroxyproline was used to determine the efficiency of elution. Hydroxyproline and hydroxylysine were also determined colorimetrically $(23,24)$.

In addition to the determination of the specific activity of cartilage hydroxyproline, the medium of the incubation was examined for possible hydroxyproline-containing collagen products. A two-part analysis of the individual medium was accomplished; first, passing the medium through an XM50 Diaflo ultrafiltration membrane (molecular cut off, 50,000; Amicon Corp., Lexington, Mass.) and second, by dialysis of the ultrafiltration effluent in dialysis tubing. In both instances, the resultant fractions were hydrolyzed in $6 \mathrm{~N} \mathrm{HCl}$ for $18 \mathrm{~h}$ at $110^{\circ} \mathrm{C}$ and analyzed as described above for hydroxyproline and counts per minute associated with hydroxyproline after thin-layer chromatographic separation.

To examine the possibility that collagen synthesis might vary in the different zones of cartilage (under the assumption that loss of the surface which occurs with moderate or moderately severe osteoarthritis may increase the specific activity of that tissue remaining by eliminating a pool of relatively stable collagen), a separate experiment was performed. Cartilage was removed from four sites (weight bearing and nonweight bearing) of a normal femoral head (obtained from a patient undergoing an Austin-Moore prosthetic replacement). Each cartilaginous site was carefully divided with a scalpel into three zones: superficial, middle, and deep, of approximately equal size. Each zone was separately analyzed for hydroxyproline as described in Methods.

\section{RESULTS}

The 45 small segments of cartilage were graded by the histological-histochemical grading system (Table I) and found to range from 0 to 14 on the scale. The 7 normal segments all fell in the $0-2$ range and, for ease of reporting, the 38 osteoarthritic samples were separated into five numerical groups (see Table III).

Table II compares the mean values of the biochemical data for the 7 normal and 38 osteoarthritic cartilage segments. As can be observed, there are no significant differences between the concentrations of DNA, hydroxyproline, or hydroxylysine in the two groups. Hydroxylysine/hydroxyproline ratios are shown in the last column of Table II. Further examination of the biochemical data for the osteoarthritic tissues, analyzed by subgroups according to their histological-histochemical grade, revealed that there were also no significant differences in the various parameters studied (Table III) with the exception of the five samples graded 12-14. In this group, hydroxyproline content was significantly higher than
TABLE II

Biochemical Analysis of Normal and Osteoarthritic Human Cartilage

\begin{tabular}{lcccc}
\hline & DNA & $\begin{array}{c}\text { Hydroxy- } \\
\text { proline }\end{array}$ & $\begin{array}{c}\text { Hydrox- } \\
\text { ylysine }\end{array}$ & $\begin{array}{c}\text { Ratio\$ } \\
\text { Hydroxylysine/ } \\
\text { Hydroxyproline }\end{array}$ \\
\hline \multicolumn{5}{c}{$\mu / \mathrm{mg}$ dry wt } \\
$\begin{array}{l}\text { Normal (7) } \\
\begin{array}{l}\text { Osteoar- } \\
\text { thritic (38) }\end{array}\end{array}$ & $4.27 \pm 0.7^{*}$ & $69.5 \pm 13$ & $9.65 \pm 1.4$ & 0.139 \\
& $\mathrm{NS} \ddagger$ & $\mathrm{NS}$ & $\mathrm{NS}$ & $\mathrm{NS}$ \\
\hline
\end{tabular}

* Mean and SD.

\$ As determined by the paired $t$ test.

$\$$ It should be noted that these ratios were obtained by comparing the concentrations of the amino acids on a microgram per milligram basis rather than on the more commonly used residues per 1,000 so that the values are not comparable to those reports which are based on that type of calculation. (When expressed as residues, the mean values for the ratios approximate 0.092 and 0.100 for normal and osteoarthritic cartilage, respectively.

the normal group, but the ratio of hydroxylysine/ hydroxyproline was not significantly different.

Analysis of the metabolic data for the normal and osteoarthritic articular cartilage segments indicated that $\left[{ }^{3} \mathrm{H}\right]$ proline incorporation (TCA-insoluble material) was significantly increased in osteoarthritic tissues as compared to normal (Table IV). This almost fourfold increase is presumably in large measure a reflection of the increment in the rate of synthesis of proteoglycan $(15,16)$. A more specific indicator of collagen turnover is the measurement of the specific activity of hydroxyproline (25) and the highly significant sixfold increase in the osteoarthritic cartilages (Table IV) suggests that collagen synthesis in these tissues is substantially greater than in the nonosteoarthritic tissues.

Variations in $\left[{ }^{3} \mathrm{H}\right]$ proline incorporation into osteoarthritic cartilage with advancing histological-histochemical grade is demonstrated graphically in Fig. 1. All of the sample groups show increased values compared with the normals and show progressive increments with advancing severity up to a histological grade of $8-10$, beyond which the level falls. Similarly, Fig. 2 compares the variation in specific activity of hydroxyproline in osteoarthritic cartilage against the histologic grade for the 38 tissue segments. As with the incorporation of $\left[{ }^{3} \mathrm{H}\right]$ proline, the specific activity of hydroxyproline from osteoarthritic cartilages advances significantly to the grade of 6-8 after which the values fall off. The widest ranges noted are for the five samples in the 12-14 group, an indication perhaps of the heterogeneous nature of tissues at this severe degree of osteoarthritis. 
TABLE III

Biochemical Analysis of Normal and Osteoarthritic Human Cartilage According to Histological-Histochemical Grading

\begin{tabular}{ccccc}
\hline $\begin{array}{c}\text { Histological-histo- } \\
\text { chemical grade } \\
\text { (number of samples) }\end{array}$ & DNA & Hydroxyproline & Hydroxylysine & $\begin{array}{c}\text { Ratio } \\
\text { Hydroxylysine/ } \\
\text { Hydroxyproline }\end{array}$ \\
\hline & & $\mu g / m g d r y w t$ & & \\
Normal (7) & $4.27 \pm 0.7 *$ & $69.5 \pm 10$ & $9.65 \pm 1.4$ & 0.139 \\
Osteoarthritic (38) & & & & \\
$0-2(5)$ & $4.39 \pm 0.8$ & $72.6 \pm 13$ & $9.70 \pm 1.6$ & 0.134 \\
$3-5(12)$ & $4.09 \pm 0.7$ & $74.5 \pm 10$ & $11.7 \pm 1.0$ & 0.157 \\
$6-8(13)$ & $4.25 \pm 1.0$ & $75.5 \pm 14$ & $11.8 \pm 1.3$ & 0.156 \\
$9-11(3)$ & $3.76 \pm 0.5$ & $76.4 \pm 7$ & $12.4 \pm 2.3$ & 0.162 \\
$12-14(5) \S$ & $4.68 \pm 0.8$ & $106.5 \pm 5 \ddagger$ & $12.7 \pm 1.8$ & 0.128 \\
& & $(P<0.001)$ & & $(P>0.10)$ \\
\hline
\end{tabular}

* Mean \pm SD.

‡ Determined by independent paired $t$ test.

$\S$ This last group showed marked heterogeneity of tissue structure and was presumed to be contaminated with repair tissue (20).

Analysis of the media revealed that insignificant amounts of hydroxyproline were present $(<1 \mu \mathrm{g} / \mathrm{mg}$ dry wt tissue incubated). Of the total TCA-insoluble, nondialyzable radioactivity present in the media, $22 \%$ was associated with hydroxyproline; the remainder presumably reflects $\left[{ }^{3} \mathrm{H}\right]$ proline incorporation into both proteoglycans and soluble collagen. When the ratio between the incorporated radioactivity into cartilage and that in the media (per milligram cartilage incubated) was calculated, the results approximated a value of 1.60 and did not vary between normal and osteoarthritic tissues or with the degree of severity of the osteoarthritic lesion. In addition, there was no correlation between the amount of radioactivity associated with hydroxyproline in the

\section{TABLE IV}

Metabolic Activity for Proline and Hydroxyproline in Normal and Osteoarthritic Human Cartilage

\begin{tabular}{|c|c|c|}
\hline & $\begin{array}{l}\left.{ }^{[} \mathrm{H} H\right] \text { Proline } \\
\text { incorporation }\end{array}$ & $\begin{array}{l}\text { Specific activity, } \\
\text { hydroxyproline }\end{array}$ \\
\hline & 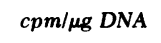 & $c p m{ }^{3} H / \mu M$ \\
\hline \multirow[t]{2}{*}{$\begin{array}{l}\text { Normal (7) } \\
\text { Osteoarthritic (38) }\end{array}$} & $\begin{array}{l}181 \pm 28^{*} \\
7.10 \pm 150\end{array}$ & $\begin{array}{r}447 \pm 177 \\
2937 \pm 717\end{array}$ \\
\hline & $P<0.005 \ddagger$ & $P<0.005$ \\
\hline
\end{tabular}

* Mean \pm SD.

$\ddagger$ As determined by Student's $t$ test.

$\left[{ }^{3} \mathrm{H}\right]$ Proline radioactivity measured in the TCA-insoluble fraction of homogenized normal and osteoarthritic cartilage. Specific activities of hydroxyproline measured after acid hydrolysis and thin-layer chromatography separation of hydroxyproline. media (per milligram tissue incubated) and the degree of severity of the osteoarthritic lesion or between this value and the normal vs. osteoarthritic group. However, a difference in the distribution of total radioactivity in the media was noted in that the media from osteoarthritic cartilage incubations contained larger amounts of labeled, low molecular weight material whereas that from the normals had increased

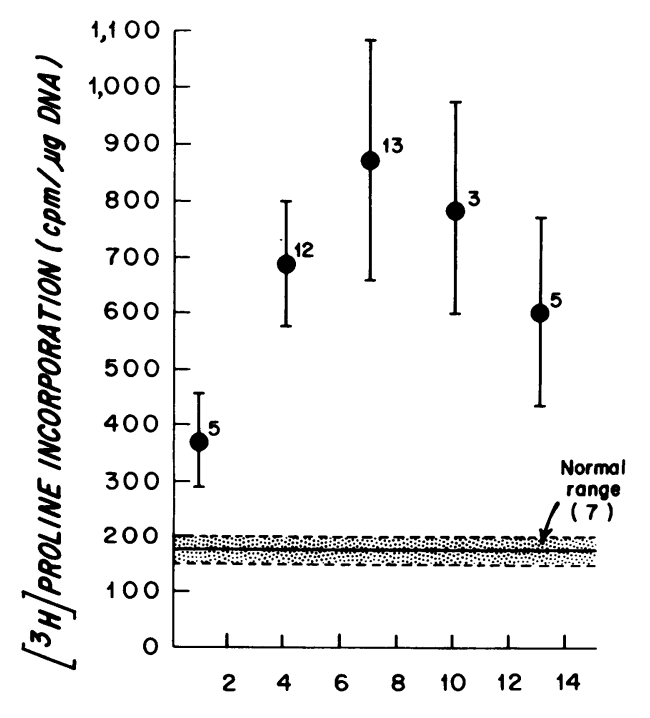

HISTOLOGICAL-HISTOCHEMICAL GRADE

FIGURE $1\left[{ }^{3} \mathrm{H}\right]$ Proline incorporation into normal and osteoarthritic cartilage: variation with histological-histochemical grade. Incorporated radioactivity represents that portion of labeled substrate associated with TCA-insoluble material of tissue homogenates after a 6-h incubation in Ham's F-12 media. 
concentrations of labeled, higher molecular weight material (Table V).

Examination of the collagen synthetic rate at different depths of cartilage indicated that the specific activity of hydroxyproline was greater in the lower zones of the tissue (Table VI) but, as can be seen, the concentration of hydroxyproline is elevated in the upper levels of tissue so that the change in specific activity is a result of the increased concentration of hydroxyproline in the superficial zones of the tissue.

\section{DISCUSSION}

The biochemical data reported in this study show no change in the content of hydroxyproline or hydroxylysine (or the derived ratios) in osteoarthritic cartilage as compared with normals or variation in these values with increasing severity of the disease process. This suggests that collagen metabolism is in balance and the material produced is qualitatively homogeneous. In terms of the metabolic aspect, the fixed value for collagen content can only be reconciled with the data showing a sixfold increment in specific activity of hydroxyproline by two possible explanations. The first is that the observed anabolic activity is of such a low order of magnitude that it has little effect on the gross collagen content of the tissue. Since the study does not provide sufficient data for a balance experiment, little can be said to refute or deny this possibility. The second and probably more likely possibility is that a collagenase, now thought to be present in osteo-

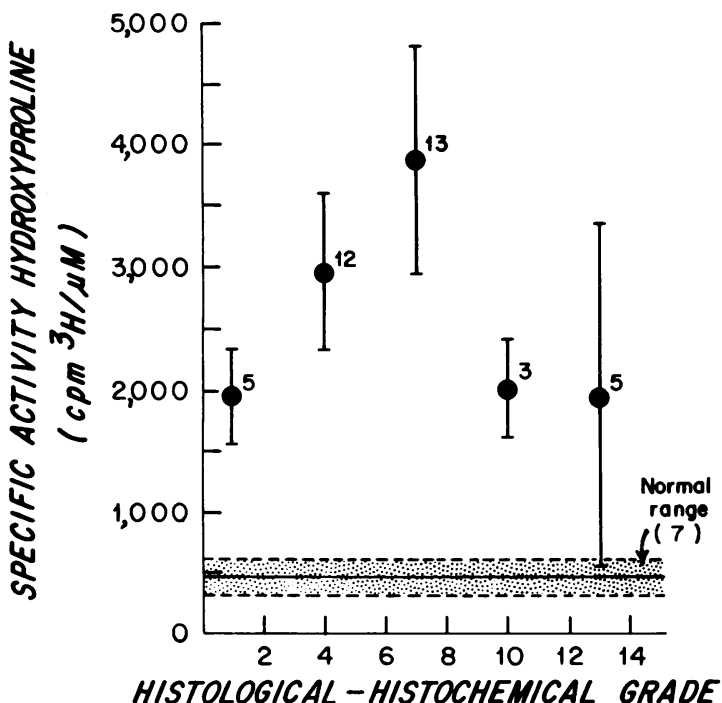

FIGURE 2 Specific activity of hydroxyproline in normal and osteoarthritic cartilage: variation with histological-histochemical grade. Specific activity of hydroxyproline determined after hydrolysis of cartilage segments in $6 \mathrm{~N} \mathrm{HCl}$ and subsequent separation of hydroxyproline from proline by thin-layer chromatography.
TABLE V

Comparison of the Distribution of Radioactivity between Cartilage and Media

\begin{tabular}{|c|c|c|}
\hline \multirow[b]{2}{*}{ Fraction } & \multicolumn{2}{|c|}{$\begin{array}{l}\text { Ratio } \mathrm{cpm} / \mathrm{mg} \text { cartilage/cpm media/ } \\
\text { mg cartilage }\end{array}$} \\
\hline & XM-50 & $\begin{array}{l}\text { Dialyzed effluent } \\
\text { of XM-50 }\end{array}$ \\
\hline Normal (7) & $0.44 \pm 0.02 *$ & $2.66 \pm 0.25$ \\
\hline Osteoarthritic (38) & $3.03 \pm 0.42$ & $0.37 \pm 0.02$ \\
\hline
\end{tabular}

* Mean \pm SD.

Radioactivity in the individual media was determined after a 6-h incubation of cartilage in Ham's F-12 media containing $100 \mu \mathrm{C}\left[{ }^{3} \mathrm{H}\right]$ proline. The retente of the XM-50 ultrafiltration (molecular cutoff, 50,000) was counted after diafiltration. The effluent of the XM-50 filtration was dialyzed in dialysis tubing (molecular cutoff $\cong 10,000$ ) for $48 \mathrm{~h}$ at $4^{\circ} \mathrm{C}$ and radioactivity determined after volume reduction by lyophilization. Values were normalized by dividing the total amount of counts per minute in the media by the total weight of tissue incubated and expressed as the ratio of counts per minute taken up by the tissue to counts per minute in the media per milligram tissue incubated.

arthritic cartilage (12) is operating catabolically at a rate equivalent to the anabolic rate observed in this study and thus maintaining the balance. This would tend to support the thesis advanced by Ehrlich et al. (12) that autolytic collagen degradation is a major component of the osteoarthritic process, particularly in more severe phases of the disease.

Miller and Matukas $(26,27)$ and several subsequent investigators $(28,29)$ have demonstrated that cartilage contains a different genetic species of collagen than that found in skin and bone. The collagen of cartilage (type II) has a number of differences from that found in skin and bone (type I), including an in-

TABLE VI

Incorporation of $\left[{ }^{3} \mathrm{H}\right]$ Proline into Hydroxyproline at Different Depths of Normal Articular Cartilage

\begin{tabular}{lccc}
\hline \multicolumn{1}{c}{ Zone } & Hydroxyproline & Hydroxyproline & $\begin{array}{r}\text { Specific activity } \\
\text { hydroxyproline }\end{array}$ \\
\hline & $\mu g / m g$ & $d p m / \mu g$ DNA & $d p m / \mu m$ \\
Superficial (4) & $113 \pm 2^{*}$ & $126 \pm 18$ & $715 \pm 35$ \\
Middle (4) & $94 \pm 6$ & $113 \pm 20$ & $1075 \pm 95$ \\
Deep (4) & $85 \pm 5$ & $120 \pm 2$ & $1084 \pm 68$
\end{tabular}

* Mean \pm SD.

Cartilage from four sites of a normal femoral head was divided into superficial, middle, and deep zones of approximately equal thickness and incubated for $6 \mathrm{~h}$ in Ham's F-12 media containing $100 \mu \mathrm{Ci}\left[{ }^{3} \mathrm{H}\right.$ ]proline. Radioactivities associated with hydroxyproline were determined after acid hydrolysis and thin-layer chromatographic separation. 
crease in the number of hydroxylysine residues per chain. The hydroxylysine values reported for cartilage collagen range as high as 24 residues per 1,000 residues (26-28) (as compared with 4 in type I collagen), but others have reported lower values $(3,29)$. The values reported in this study are consistent with those reported by Miller et al. (3) and are certainly greater than the anticipated figure for type I collagen. They most likely reflect either type II alone or conceivably, a mixture of type I and type II (31). It is of some interest that recently Fukae et al. (30) have described a chromatographically different type II collagen from osteoarthritic human cartilage and these authors suggest that altered metabolism in osteoarthritic cartilage may result in a different hydroxylysine/hydroxyproline ratio than that found in normal cartilage.

Of greater importance than the absolute number, however, is the fact that the hydroxylysine/hydroxyproline ratio does not change with advancing severity of the disease. Since the majority of cases of osteoarthritis are considered to be chronic disorders, requiring decades for development, it is plausible to assume that tissues taken from patients in their fifth and sixth decade would contain a sufficient amount of collagen which would be characteristic of the disease process. Therefore, measurement of the hydroxylysine/hydroxyproline ratio in these tissues would provide an index of the type of collagen being synthesized over many years. Although the data presented here do not support the concept that osteoarthritis is associated with a shift by the chondrocyte from synthesis of type II collagen to type I, (as reported by Nimni and Deshmukh [31]), it is still possible that the volume of the altered synthetic activity is so small as to not be detectable by our study.

The metabolic data clearly demonstrate that a significant increase in the specific activity of insolubilized collagen occurs in osteoarthritic human articular cartilage after short $(6 \mathrm{~h})$ exposure to a labeled substrate. This suggests that the synthetic activity of collagen in osteoarthritis is markedly increased and further, that this increase varies directly with the severity of the disease process through grade $6-8$ and then varies inversely as the lesions become more severe.

A second observation can be made on the basis of the $\left[{ }^{3} \mathrm{H}\right]$ proline incorporation study (Table IV) which indicated a fourfold overall increase in the osteoarthritic cartilage as compared with the normal. Since proline (unlike hydroxyproline) is rather ubiquitously distributed in structural and other proteins, these data can not be interpreted as indicating an alteration in collagen synthesis alone, but more likely indicate an overall increase in the rate of protein synthesis by the chondrocyte under the stimulus of osteoarthritis. Since the protein of proteoglycan is quite rich in proline (4), it is probable that the observed increase is based principally on the increased turnover of this macromolecule. Previously reported data from this and other laboratories have shown that proteoglycan synthesis is markedly increased in osteoarthritic cartilage (14-16) and that the increment varies directly with the severity of the process as determined by the histological-histochemical grade (16). The shape of the curve reported for ${ }^{35} \mathrm{SO}_{4}$ incorporation into osteoarthritic cartilages of different grades of severity is quite similar to that seen in Fig. 1 (16), supporting the concept that the change seen in $\left[{ }^{3} \mathrm{H}\right]$ proline incorporation into cartilage and the radioactivity in the media reflect mostly proteoglycan metabolism.

Prior studies have also shown that the superficial zone of normal articular cartilage is poor in proteoglycan $(18,32)$ (and rich in collagen [11]) and that the cells of this area more closely resemble fibroblasts than chondrocytes on electron microscopy (11). These data suggest that this region is a zone of increased rather than decreased collagen synthesis and one can speculate that removal of this zone (as in moderately severe osteoarthritis) would be reflected by a diminution in the specific activity of hydroxyproline rather than an increase. On the basis of our results, the specific activity of hydroxyproline is higher in the lower zones of articular cartilage (Table VI) but, as indicated above, this may not be a significant change. In addition, the difference in specific activity of hydroxyproline between the upper and middle zones is less than $35 \%$ which would seem insignificant when compared to the observed $600 \%$ increase observed in the osteoarthritic tissue (Table IV). Based upon these data, it would seem unreasonable to attribute the increase in hydroxyproline specific activity in osteoarthritic cartilage to fibrillation and (or) erosion of the superficial layers of cartilage.

Interpretation of our data on the increased specific activity of hydroxyproline in osteoarthritic cartilages takes into account several possible sources of error in experimental design. The first is the possibility of the existence of variations in the intra- or extracellular proline pools between osteoarthritic and normal cartilage and also variations in these pools at different stages of the disease process. To minimize this error (if it exists) and also to reduce the likelihood that the data reflect a recycling of labeled proline breakdown products, we chose Ham's F-12 medium which contains $0.3 \mathrm{mmol}$ of proline. This value is surely greater than the biological pools for proline and therefore would decrease the possibility of obtaining variations in hydroxyproline specific activity as a result of changes in the intracellular and extracellular proline pools.

A second source of error is related to the solubility of the collagen molecule. The study was designed to 
exclude the pro- and tropocollagen molecules since these are presumed to be washed out of the tissue either by the 6-h incubation period or the 18-h wash with cold proline solution. Subsequent analysis of both these solutions revealed that essentially no hydroxyproline was present in the 18 -h wash but small amounts of hydroxyproline-containing material of high specific activity were present in the incubation medium. No attempt was made to characterize this material because of the very low levels present, but it is probable that the radioactivity was present in hydroxyproline-containing collagen fragments and (or) procollagen molecules.

Our data on the specific activity of hydroxyproline represents only that fraction of labeled hydroxyproline contained in the insolubilized collagen of the matrix of cartilage. However, if more or less of the collagen of osteoarthritic cartilage is soluble than that from normal, this could theoretically introduce a serious source of error. Data from the literature suggest, however, that less than $3 \%$ of the collagen of cartilage is soluble in cold salt solutions and, as has been reported by both Miller et al. (3) and McDevitt (2), there is no change in this value in osteoarthritis. This is in rather sharp contrast to the data reported by Brandt (33) for proteoglycans from osteoarthritic cartilage, which demonstrate a considerable increase in solubility.

In final summary, our data indicate that collagen synthesis in osteoarthritic human cartilage is increased as compared with normal cartilage and, further, that the rate of collagen synthesis seems to vary with the severity of the disease as determined by the histological-histochemical grading system. Collagen content and hydroxylysine/hydroxyproline ratios remain unchanged in the osteoarthritic tissue, suggesting first that the collagen product, although not the same, may not be a type I genetic species and, second, that degradation (presumably enzymatic destruction by collagenase) keeps pace with the anabolic phase. It can be speculated that in late phases of osteoarthritis, the catabolic process exceeds the anabolic process leading to end-stage osteoarthritis with complete cartilage loss.

\section{ACKNOWLEDGMENT}

This research was supported in part by research grant AM16265 from the National Institutes of Arthritis, Metabolism, and Digestive Diseases.

\section{REFERENCES}

1. Muir, H. 1973. Biochemistry. In Adult Articular Cartilage. M. A. R. Freeman, editor. Grune \& Stratton, New York. 100-130.

2. McDevitt, C. A. 1973. Biochemistry of articular cartilage. Nature of proteoglycans and collagen of articular cartilage and their role in aging and osteoarthrosis. Ann. Rheum. Dis. 32: 364-378.

3. Miller, E. J., J. K. van der Korst, and L. Sokoloff. 1969. Collagen of human articular and costal cartilage. Arthritis Rheum. 12: 21-29.

4. Rosenberg, L. 1975. Structure of cartilage proteoglycans. In Dynamics of Connective Tissue Macromolecules. P. M. C. Burleigh and A. R. Poole, editors. American Elsevier Publishing Co., Inc., New York. 105-124.

5. Mankin, H. J. 1975. The metabolism of articular cartilage in health and disease. In Dynamics of Connective Tissue Macromolecules. P. M. C. Burleigh and A. R. Poole, editors. American Elsevier Publishing Co., Inc., New York. 372-358.

6. Mankin, H. J. and L. Lippiello. 1969. The turnover of adult rabbit articular cartilage. J. Bone Jt. Surg. Am. Vol. 51: $1591-1600$.

7. Barrett, A. J. 1975. The enzymatic degradation of cartilage matrix. In Dynamics of Connective Tissue Macromolecules. P. M. C. Burleigh and A. R. Poole, editors. American Elsevier Publishing Co., Inc., New York. 189-215.

8. Ali, S. Y., L. Evans, E. Stainthorpe, and C. H. Lack. 1967. Characterization of cathepsins in cartilage. Biochem. J. 105: 549-557.

9. Woessner, J. F., Jr. 1973. Cartilage cathepsin D and its action on matrix components. Fed. Proc. 32: 1485-1488.

10. Sapolsky, A. I., R. D. Altman, J. F. Woessner, and D. S. Howell. 1973. The action of cathepsin D in human articular cartilage on proteoglycans. J. Clin. Invest. 52: 624633.

11. Weiss, C., L. Rosenberg, and H. J. Helfet. 1968. An ultrastructural study of normal young adult human articular cartilage. J. Bone Jt. Surg. Am. Vol. 50: 663-674.

12. Ehrlich, M. G., H. J. Mankin, H. Jones, R. Wright, and C. Crispen. 1975. Collagenase and collagenase inhibitors in osteoarthritic and normal human cartilage. J. Bone Jt. Surg. Am. Vol. 57: 570. (Abstr.)

13. Repo, M. U., and N. Mitchell. 1971. Collagen synthesis in mature articular cartilage of the rabbit. J. Bone Jt. Surg. Br. Vol. 53: 541-548.

14. Bollet, A. J., J. R. Handy, and B. C. Sturgill. 1963. Chondroitin sulfate concentrations and protein-polysaccharide composition of articular cartilage in osteoarthritis. J. Clin. Invest. 42: 853-859.

15. Mankin, H. J. and L. Lippiello. 1970. Biochemical and metabolic abnormalities in articular cartilage from osteo-arthritic human hips. J. Bone Jt. Surg. Am. Vol. 52: 424-434.

16. Mankin, H. J., H. Dorfman, L. Lippiello, and A. Zarins. 1971. Biochemical and metabolic abnormalities in articular cartilage from osteo-arthritic human hips. II. Correlation of morphology with biochemical and metabolic data. J. Bone Jt. Surg. Am. Vol. 53: 523-537.

17. Ali, S. Y. and L. Evans. 1973. Enzymatic degradation of cartilage in osteoarthritis. Fed. Proc. 32: 1494-1498.

18. Howell, D. S. 1975. Degradative enzymes in osteoarthritic human articular cartilage. Arthritis Rheum. 18: 167-177.

19. Ehrlich, M. G., H. J. Mankin, and B. V. Treadwell. 1973. Acid hydrolase activity in osteoarthritic and normal human cartilage.J. Bone Jt. Surg. Am. Vol.55: 1068-1076.

20. Meachim, G. and G. V. Osborne. 1970. Repair of the femoral articular surface in osteo-arthritis of the hip. J. Pathol. 102: 1-8 (and plates I-IV).

21. Bonting, S. L. and M. Jones. 1957. Determination of microgram quantities of deoxyribonucleic acid and protein in tissues grown in vitro. Arch. Biochem. Biophys. 66: 340-353. 
22. Chiari, D., M. Röhr, and G. Widtmann. 1965. TLC $R_{F}$ values of amino acids. Mikrochim. Ichnoanal. Acta. (quoted in 1966.J. Chromatogr. 23 [Suppl. D3]: 672). 1973.

23. Blumenkrantz, N. and G. Asboe-Hansen. 1973. An improved method for the assay of hydroxylysine. Anal. Biochem. 56: 10-15.

24. Woessner, J. F., Jr. 1961. The determination of hydroxyproline in tissue and protein samples containing small portions of this amino acid. Arch. Biochem. Biophys. 93: $440-447$.

25. Stetten, M. R. and R. Schoenheimer. 1944. Metabolism of 1-proline studied with aid of deuterium and isotopic nitrogen. J. Biol. Chem. 153: 113-132.

26. Miller, E. J. and V. J. Matukas. 1969. Chick cartilage collagen: a new type of $\alpha$ l chain not present in bone or skin of the species. Proc. Natl. Acad. Sci. U. S. A. 64: 1264-1268.

27. Miller, E. J. 1971. Isolation and characterization of a collagen from chick cartilage containing three identical $\alpha$ chains. Biochemistry. 10: 1652-1659.

28. Strawich, E., and M. E. Nimni. 1971. Properties of a collagen molecule containing three identical com- ponents isolated from bovine articular cartilage. Biochemistry. 10: 3905-3911.

29. Seyer, J. M., D. M. Brickley, and M. J. Glimcher. 1974. The identification of two types of collagen in the articular cartilage of postnatal chickens. Calcif. Tissue Res. 17: 43-55.

30. Fukae, M., G. L. Mechanic, L. Adamy, and E. R. Schwartz. 1975. Chromatographically different type II collagens from human normal and osteoarthritic cartilage. Biochem. Biophys. Res. Commun. 67: 1575-1580.

31. Nimni, M. and K. Deshmukh. 1973. Differences in collagen metabolism between normal and osteoarthritic human articular cartilage. Science (Wash.D. C.). 181: 751752.

32. Maroudas, A., H. Evans, and L. Almeida. 1973. Cartilage of the hip joint. Topographical variations of glycosaminoglycan content in normal and fibrillated tissue. Ann. Rheum. Dis. 32: 1-9.

33. Brandt, K. D. 1974. Enhanced extractability of articular cartilage proteoglycans in osteoarthrosis. Biochem. J. 143: $475-478$ 